\title{
Physical activity levels, lesson context, and teacher behaviours in elementary physical education classes taught by paraeducators
}

\author{
James C. Hannon ${ }^{1}$, Fitni Destani ${ }^{2}$, Brian McGladrey ${ }^{3}$, Skip M. Williams ${ }^{4}$, Grant Hill ${ }^{5}$ \\ ${ }^{1}$ University of Utah, Salt Lake City, UT, USA \\ ${ }^{2}$ Keene State University, Keene, NH, USA \\ ${ }^{3}$ Weber State University, Ogden, UT, USA \\ ${ }^{4}$ Illinois State University, Normal, IL, USA \\ ${ }^{5}$ California State University Long Beach, Long Beach, CA, USA
}

\section{Email address:}

james.hannon@hsc.utah.edu (J. C. Hannon),fdestani@keene.edu (F. Destani), brianmcgladrey@weber.edu (B. McGladrey), swillia@ilstu.edu (S. Williams), grant.hill@csulb.edu (G. Hill)

\section{To cite this article:}

James C. Hannon, Fitni Destani, Brian McGladrey, Skip M. Williams, Grant Hill. Physical Activity Levels, Lesson Context, and Teacher Behaviours in Elementary Physical Education Classes Taught by Paraeducators. International Journal of Elementary Education.

Vol. 2, No. 3, 2013, pp. 23-26. doi: 10.11648/j.ijeedu.20130203.11

\begin{abstract}
In the USA some states permit the use of paraeducators to teach elementary physical education. These paraeducators are typically poorly trained and have little experience in the subject matter. There have been few studies examining the potential effects of professional development with paraeducators. The purpose of this study was to determine the physical activity levels, lessons context, and teacher behaviors of paraeducators who had received varied amounts of professional development training. A total of 18 paraprofessionals from a potential sample of 54 were randomly selected to be observed teaching physical education using the System for Observing Fitness Instruction Time (SOFIT). ANOVA results indicated no significant differences by years of teacher training in each SOFIT category. Overall, children spent the majority of time in class standing (42.8\%) and were only moderately-to-vigorously active for $32.1 \%$ of the class time, well below the national recommendation of $50 \%$ of class time. These results demonstrate that professional development is not enough to prepare paraeducators to teach elementary physical education. Only licensed and qualified teachers who complete professional training programs should be hired to teach in schools.
\end{abstract}

Keywords: Professional Development, Paraeducator, Physical Education

\section{Introduction}

According to the recent Shape of the Nation Report, 83\% percent of states mandate elementary physical education and $78 \%$ of states require the teachers delivering physical education at the elementary school level to hold a teacher licensure/certification [1]. Holding a licensure/certification does not guarantee that the teachers are endorsed in physical education. Many of the teachers delivering physical education are non-specialist classroom teachers. Unfortunately, many of these non-specialist classroom teachers may have received little to no training in physical education [2]. A disturbing yet under-reported and unstudied trend is for schools in states without licensure/certification requirements to hire paraeducators to deliver physical education. Although paraeducators have been part of the public school system for over 40-years, their role in physical education has typically been to assist the trained specialist [3]. They are generally not familiar with proper physical education curriculum [4]. In fact, their primary training would have come from their own experiences as children. Thus, they enter the teaching arena with a subjective warrant based on experiences that could have been either positive or negative.

Descriptive research studies have reported that even the teaching behaviors of elementary school classroom teachers delivering physical education are not always effective. In particular, students' engagement time in skill practice was found to be low, and it was found that students typically participated as an entire class in game-type activities [2, 5]. In studies comparing differences between physical 
education specialists and non-specialist elementary classroom teachers, physical education specialists exhibited significantly higher levels of effective teaching behaviors and had significantly higher levels of student physical activity in classes [2, 5-6]. Studies have also reported that physical education specialists have more of the specific skills and provide significantly more feedback statements during their lessons [7-8].

Although studies have shown that elementary physical education is more effectively delivered by trained specialists the reality is that many states do not require specialists. It may be argued that with proper training non-specialist paraeducators could provide quality instruction in physical education. In fact, teacher development is well recognized as being critical to successful instructional improvement [9]. The inadequate training and knowledge of paraeducators limits their abilities to meet the educational needs of their students [3]. The purpose of this study was to determine the physical activity levels, lesson context, and teacher behaviors in elementary physical education classes taught by in-service workshop trained and untrained paraeducators.

\section{Methods}

\subsection{Participants and Setting}

A total of 18 paraeducation professionals and their classes were selected to be observed from a pool of 54 teachers in a large southwestern U.S. school district. The school district hires paraeducators to teach physical education for 20 hours per week in each of the district's 54 elementary schools. The paraeducators are required to attend a yearly 8-hour workshop focused on elementary physical education activities designed to emphasize physical activity/fitness. The workshops are delivered by three physical education specialists employed by the district's main office. The school district approved of this study because they were interested in gauging the effectiveness of their training program. Prior to the start of the study the district coordinator for physical education met with the researchers to discuss the procedures and observation schedule. It was decided that all 54 teachers would be placed into three categories based on years of training (0, 1-3, \& 4-7 years). Six teachers were then randomly selected from each category, representing one-third of the paraeducators teaching in the district's elementary schools. Seventeen of the teachers were females and one was a male. None of the teachers possessed a bachelor's degree in education.

\subsection{Instrumentation}

The System for Observing Fitness Instruction Time (SOFIT) was used to obtain information on student physical activity levels (lying down, sitting, standing, walking, and very active), the lesson context in which they occurred (management, general knowledge, physical fitness knowledge, fitness, skill practice, game play, free play), and the teacher involvement (promotes fitness, demonstrates fitness, instructs generally, manages, observes, or other task). According to previous research, the SOFIT is considered a valid observation instrument to measure physical activity in physical education classes [10].

Three doctoral students and one master's student enrolled in a course on the use of systematic observation in physical education/physical activity settings were trained to use the SOFIT system. Observer training consisted of a formal presentation on the development and use of the SOFIT system, class readings, literature synthesis, and discussions on the use of SOFIT in previous research studies. Observers studied SOFIT definitions and coding conventions outside of class. Finally, practice coding vignettes from videotapes of physical education classes were completed with a trainer. Additionally, inter-rater reliability was checked throughout the data collection period, using procedures described by McKenzie [11]. Inter-rater reliability for the different activity levels varied from .96 to 1 , for the lesson contexts from .95 to 1 , and for teacher behavior from .90-1.

\subsubsection{Procedures}

Each paraeducator was observed teaching a $4^{\text {th }}$ and $5^{\text {th }}$ grade physical education class. All coding took place live in each school's indoor activity area. Observers arrived at the instructional site at least 10 minutes prior to class time. The observers were equipped with pencils, a clipboard, observation sheets, a mini-tape player, and a pre-recorded audio-tape to pace the observations.

Based on McKenzie, Sallis, and Nader [12], physical activity, lesson contexts, and teacher behaviors were observed using a $10 \mathrm{~s}$ observe, $10 \mathrm{~s}$ record interval format. In line with the SOFIT instructions [12], the actual physical education lesson time started when $51 \%$ of the pupils had reached the instructional area and ended when half of the class had departed from the area. In line with the SOFIT protocol [12], students were selected to be observed as they arrived in the instructional area. Five students representative of the class were selected, including at least two boys and two girls. Four students were used as the primary observation targets with the fifth student acting as a back-up if one of the other students left the observation area. Observers noted identifying characteristics of each student on the SOFIT lesson observation form. Coding began with four minutes of observation of student one, followed by student two, and continued sequentially until the end of class time.

\subsubsection{Data Analysis}

Statistical analysis for all data in this study was conducted on a personal computer using SPSS version 15.0 software (SPSS, Inc., Chicago, IL, USA). Data were initially entered into an Excel spread sheet and confirmed by another researcher to assure reliability of the data input. Descriptive statistics were used to summarize the percentage of time spent in each physical activity, lesson context, and teacher behavior category by years of teacher training. In addition, analysis of variance (ANOVA) procedures were used to determine whether there were significant differences in each 
SOFIT category by years of teacher training. The level of statistical significance was set at $p<.05$.

\section{Results}

Table 1 presents the percentages of physical education class time spent at various physical activity levels, different lesson contexts, and teacher behaviors by years of teacher training. No significant differences were found by years of teacher training within each SOFIT category (Table 1). On average, when combining all classes, students engaged in MVPA for $32.1 \%$ of class, well below the Healthy People 2020 [13] recommendation of 50\%. The most common activity was standing (42.8\%). A majority of the lesson context was spent in game play $(29.9 \%)$ and general content knowledge $(28.4 \%)$. The most common teacher behaviors were instructs generally $(57.7 \%)$ and manages $(21.2 \%)$.

Table1. Percent of class time in SOFIT categories by years of teacher training/experience

\begin{tabular}{|c|c|c|c|c|}
\hline & 0 Years & 1-3 Years & 4-7 Years & p-value \\
\hline \multicolumn{5}{|l|}{ Physical Activity Levels: } \\
\hline Lying Down (1) & $.30 \pm .47$ & $.28 \pm .69$ & $.20 \pm .32$ & .938 \\
\hline Sitting(2) & $14.8 \pm 8.9$ & $34.3 \pm 14.8$ & $25.1 \pm 20.4$ & .124 \\
\hline Standing (3) & $53.0 \pm 13.6$ & $34.7 \pm 11.1$ & $40.6 \pm 16.0$ & .093 \\
\hline Walking (4) & $18.6 \pm 5.9$ & $15.7 \pm 12.0$ & $16.6 \pm 7.9$ & .846 \\
\hline Very Active (5) & $13.5 \pm 7.2$ & $14.9 \pm 6.2$ & $17.6 \pm 7.6$ & .596 \\
\hline Total MVPA $(4,5)$ & $32.1 \pm 9.6$ & $30.2 \pm 9.8$ & $34.2 \pm 6.5$ & .745 \\
\hline \multicolumn{5}{|l|}{ Lesson Context: } \\
\hline Gen Content (M) & $13.7 \pm 8.9$ & $25.5 \pm 9.9$ & $12.3 \pm 9.3$ & .052 \\
\hline \multicolumn{5}{|l|}{ Knowledge Content } \\
\hline Gen Knowledge (K) & $26.4 \pm 12.6$ & $23.3 \pm 16.9$ & $35.6 \pm 13.6$ & .335 \\
\hline Fitness Knowledge (P) & $.27 \pm .43$ & $3.8 \pm 6.7$ & $1.7 \pm 4.0$ & .411 \\
\hline \multicolumn{5}{|l|}{ Motor Content } \\
\hline Fitness (F) & $11.1 \pm 9.0$ & $4.8 \pm 9.9$ & $4.5 \pm 6.0$ & .349 \\
\hline Skill practice (S) & $21.5 \pm 21.9$ & $9.3 \pm 9.7$ & $14.1 \pm 13.8$ & .434 \\
\hline Game play (G) & $26.9 \pm 26.1$ & $32.9 \pm 27.1$ & $30.1 \pm 24.1$ & .921 \\
\hline Other $(\mathrm{O})$ & $.22 \pm .53$ & $.10 \pm .24$ & $1.5 \pm 3.2$ & .384 \\
\hline \multicolumn{5}{|l|}{ Teacher Behavior: } \\
\hline Promotes fitness $(\mathrm{P})$. & $.63 \pm .75$ & $2.2 \pm 4.3$ & $1.4 \pm 2.1$ & .639 \\
\hline Demo fitness (D) & $7.1 \pm 6.5$ & $.87 \pm 1.9$ & $3.7 \pm 2.6$ & .065 \\
\hline Instructs gen (I) & $57.5 \pm 16.4$ & $52.7 \pm 12.4$ & $62.9 \pm 25.3$ & .653 \\
\hline Manages (M) & $22.9 \pm 12.6$ & $26.2 \pm 10.7$ & $14.5 \pm 12.6$ & .245 \\
\hline Observes $(\mathrm{O})$ & $10.4 \pm 10.2$ & $16.7 \pm 9.7$ & $13.9 \pm 11.9$ & .603 \\
\hline Other-task (T) & $1.4 \pm 2.0$ & $1.1 \pm 2.4$ & $3.4 \pm 5.0$ & .459 \\
\hline
\end{tabular}

\section{Discussion}

The goal of this study was to determine and compare the physical activity levels, lesson context, and teacher behaviors in elementary physical education classes taught by trained and untrained paraeducators. The results indicated that there was not a statistical difference, based on SOFIT category data, between trained and untrained paraeducators.

An important finding was that the SOFIT observations showed that the mean MVPA engagement time was less than $50 \%$ of the physical education class time, overall and for each level of teacher training. This clearly demonstrates that regardless of district training the teachers were ineffective in eliciting adequate MVPA time as recommended by Healthy People 2020 [13].

It may be that the low MVPA time was aided by ineffective practices and behaviors coded in the lesson context and teacher behaviors sections of the SOFIT. Previous research in teaching physical education has demonstrated that ineffective teaching behaviors influence student physical activity [2, 5-6]. In this study teachers spent on average over half the class time engaged in instruction and about a quarter of the class time in management. Within the lesson context category about a quarter of the time was spent in general knowledge and about a quarter of the time was spent in game play. These results are similar to those reported while observing classroom teachers teaching physical education. However, it has been demonstrated that classroom teachers can become more effective physical educators when provided with in-service training [14]. Classroom teachers have the advantage over paraeducators of having completed training as an educator. Effective teaching practices are similar in both gym and classroom settings. Understanding the application of effective teaching practices in a physical education setting may be easier to comprehend for classroom teachers.

Limitations of the present study include the limited number of physical education lessons observed, the small number of schools involved, and lack of trained specialists as a comparison group. Evaluating paraeducators in comparison to classroom teachers and physical education specialists in a larger number of schools and across a larger number of lesson observations is warranted. 
In conclusion, the results of the present study demonstrate that regardless of district training, paraeducators are ineffective in eliciting adequate amounts of MVPA in their classes. In addition, paraeducators display a number of ineffective teaching behaviors which may contribute to the low MVPA time. Children would be better served by schools hiring and supporting trained and certified physical education specialists.

\section{Acknowledgements}

We would like to acknowledge the teachers and administration of the Davis County School District for their cooperation in completing this study.

\section{References}

[1] National Association for Sport and Physical Education \& American Heart Association. (2012). 2012 Shape of the nation report: Status of physical education in the USA. Reston, VA: National Association for Sport and Physical Education.

[2] Faucette, N., McKenzie, T., \& Patterson, P. (1990). Descriptive analysis of nonspecialist elementary physical education teachers' curricular choices and class organization. Journal of Teaching in Physical Education, 9, 284-193.

[3] Bryan, R.R., McCubbin, J.A., \& van der Mars, H. (2013). The ambiguous role of the paraeducator in the general physical education environment. Adapted Physical Activity Quarterly, 29, 164-183.

[4] Horton, M.L. (2001). Utlizing paraprofessionals in the general physical education setting. Teaching Elementary Physical Education, 12(6), 22-25.

[5] Faucette, N., \& Hillidge, S. (1989). Research findings: PE specialists and classroom teachers. Journal of Physical Education, Recreation and Dance, 60, 51-54.
[6] Placek, J., \& Randall, L. (1986). Comparison of academic learning time in physical education: Students of specialists and nonspecialists. Journal of Teaching in Physical Education, 5, 157-165.

[7] Behets, D. (1996). Comparing teaching behavior during active learning time between physical education specialist and nonspecialist teachers. Journal of Classroom Interaction, $31,23-29$.

[8] Block, K., \& Beckett, K. (1990). Verbal descriptions of skill by specialists and nonspecialists. Journal of Teaching in Physical Education, 10, 21-37.

[9] Armour, K.M. \& Duncombe, R. (2004). Teachers' continuing professional development in primary physical education: lessons from present and past to inform the future. Physical Education and Sport Pedagogy, 9(1), 3-21.

[10] Rowe, P.J., Schuldheisz, J.M., \& van der Mars, H. (1997). Validation of SOFIT for measuring physical activity of fi rstto eight-grade students. Pediatric Exercise Science, 9, 136-149.

[11] McKenzie, T. L. (2002) SOFIT. System for Observing Fitness Instruction Time. Overview and training manual (San Diego, CA, San Diego State University).

[12] McKenzie, T.L., Sallis, J.F., \& Nader, P.R. (1991). SOFIT: System for Observing Fitness Instruction Time. Journal of Teaching in Physical Education, 11, 195-205.

[13] United States Department of Health and Human Services. (2010). Healthy People 2020. Washington D.C.: Government Printing Office.

[14] Faucette, N., Nugent, P., Sallis, J., \& McKenzie, T. (2002). "I'd rather chew on aluminum foil." Overcoming classroom teachers' resistance to teaching physical education. Journal of Teaching in Physical Education, 21, 287-308. 